\title{
CONTINUOUS MICROSTRUCTURAL CORRELATION OF SLAG/SUPERPLASTICIZER CEMENT PASTES BY HEAT AND IMPEDANCE METHODS VIA FRACTAL ANALYSIS
}

\author{
S. W. TANG, ${ }^{*}$, R. J. CAI, ${ }^{*}$ Z. HE, ${ }^{*}$ X. H. CAI, ${ }^{*}$ H. Y. SHAO ${ }^{\dagger}$ \\ Z. J. LI, ${ }^{\dagger}$ H. M. YANG ${ }^{\ddagger}$ and E. CHEN ${ }^{\dagger}, \S$ \\ ${ }^{*}$ State Key Laboratory of Water Resources and \\ Hydropower Engineering Science \\ Wuhan University, Wuhan, P. R. China \\ ${ }^{\dagger}$ Department of Civil and Environment Engineering \\ The Hong Kong University of Science and Technology \\ Kowloon, Clear Water Bay, Hong Kong

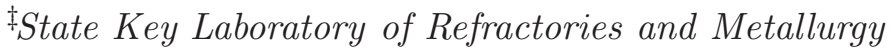 \\ Wuhan University of Science and Technology \\ Qingshan District, Wuhan, P. R. China \\ §victorymother@163.com
}

Received December 6, 2016

Revised April 11, 2017

Accepted April 17, 2017

Published May 24, 2017

\begin{abstract}
This paper presents a preliminary work to evaluate the influence of slag and superplasticizer on the early-age hydration of cement pastes by an innovative non-contact impedance measurement, heat evolution method, compressive strength and setting time tests. Besides, the cumulative pore volume obtained from modulus and phase of impedance in different hydration sections is taken to continuously correlate the cumulative heat releasing of cement pastes via the fractal
\end{abstract}

\footnotetext{
${ }^{\S}$ Corresponding author.
}

This is an Open Access article published by World Scientific Publishing Company. It is distributed under the terms of the Creative Commons Attribution 4.0 (CC-BY) License. Further distribution of this work is permitted, provided the original work is properly cited. 
analysis. Retarded phenomena and mechanism of hydration in cement pastes incorporated with slag and superplasticizer are studied, respectively. It is found that the compressive strength and setting time have a good linear relation with the slag amount in blended cement pastes.

Keywords: Cement Paste; Fractal; Slag; Superplasticizer; Pore; Hydration.

\section{INTRODUCTION}

Ordinary Portland cement (OPC)-based materials, i.e. traditional concrete materials, are the most widely used porous artificial materials due to their reliable mechanical properties. ${ }^{1}$ It is believed that the early-age hydration plays an important role in the evolution of properties of OPC-based materials. Many investigations demonstrated that the incorporation of supplementary cementitious materials and superplasticizers would accelerate or retard the hydration process of OPC-based materials to some degree. ${ }^{2} \sqrt{5}$ On the one hand, a partial replacement of Portland cement by supplementary mineral cementitious materials, such as granulated blastfurnace slag, may lead to distinct pozzolanic reactions during the hydration. ${ }^{6}$ Blast-furnace slag is a byproduct that is increasingly used for replacing part of clinker in cement! $]^{7}$ Although slag and clinker are almost composed of the same main oxides, the hydration kinetics of slag is slightly slower compared with that of clinker as slag usually contains plentiful of glassy phases with low reactivity $[8$ On the other hand, polycarboxylate-etherbased superplasticizers have drawn wide attention as they have outstanding water-reducing performance and can improve the rheological properties of cement-based materials in the premise of satisfying the construction requirements. $\frac{9}{9}$ These superplasticizers bearing $\mathrm{COO}^{-}$groups interact with cement grains through both electrostatic forces and the complexation bonding between $-\mathrm{COO}^{-}$and $\mathrm{Ca}^{2+}$. The introduction of an additional steric repulsive force by the adsorbed molecules of superplasticizers also makes great contribution to the dispersion of cement grains in the fresh status. Besides, it is proved that the pore structure of cement-based materials presents fractal features to some scale.10

However, the research findings obtained from previous works did not reveal clearly the influence of slag and superplasticizers on the early-age hydration of cement paste, especially the retardation influence. ${ }^{5[1112}$ Furthermore, the continuous kinetics correlations of hydration of cement pastes incorporated with slag or superplasticizers by different experimental methods and fractal analysis are absent.

In this work, the influence of slag and superplasticizer on the early-age hydration of cement pastes is investigated by non-contact impedance measurement (NCIM), heat evolution method, compressive strength and setting time tests. Retarded phenomena and mechanism of hydration in cement pastes are investigated. The continuous correlations of cumulative heat release and pore volume in different hydration sections are obtained to analyze the heat release and pore structure evolution by the fractal analysis.

\section{MATERIALS AND ANALYTICAL METHODS}

\subsection{Raw Materials}

In this study, OPC meeting the requirement of ASTM type I and deionized water was used. The chemical compositions and particle size distribution of cement and slag are given in Table 1 and Fig. 1. The morphologies of slag and configuration of superplasticizer are shown in Figs. 2 and 3 , respectively. Slag particles show typical angular shape in Fig. 2] while the structure of polycarboxylateether-based superplasticizer in Fig. 3 is a typical comb-like copolymer constructed by a sodium polymethacrylate backbone partially esterified with polyethyleneglycol chains.

With respect to the slag case, slag-blended cement pastes with water to binder (cement + slag) ratio of 0.4 by mass were prepared in the environmental chamber with temperature $\left(20 \pm 2^{\circ} \mathrm{C}\right)$ and humidity $(95 \pm 5 \%)$ and these pastes were noted as S0, S10, S30, S50 and S70 according to different replacement amounts of cement by slag, i.e. $0 \%, 10 \%, 30 \%, 50 \%$ and $70 \%$. These pastes were mixed and prepared in a planetary-type mixer at 45 revolutions per minute for $2 \mathrm{~min}$ first and then at 90 revolutions per minute for $2 \mathrm{~min}$.

With regard to the superplasticizer case, the water to cement ratio of cement pastes was kept constant at 0.3 . The dosages of superplasticizer were 
Table 1 The Chemical Composition of Cement and Slag (wt.\%).

\begin{tabular}{lccccccccc}
\hline $\begin{array}{l}\text { Cement } \\
\text { wt.\% }\end{array}$ & $\begin{array}{c}\mathrm{CaO} \\
62.49\end{array}$ & $\begin{array}{c}\mathrm{SiO}_{2} \\
21.24\end{array}$ & $\begin{array}{c}\mathrm{SO}_{3} \\
6.15\end{array}$ & $\begin{array}{c}\mathrm{Al}_{2} \mathrm{O}_{3} \\
4.57\end{array}$ & $\begin{array}{c}\mathrm{Fe}_{2} \mathrm{O}_{3} \\
3.02\end{array}$ & $\begin{array}{c}\mathrm{MgO} \\
1.52\end{array}$ & $\begin{array}{c}\mathrm{K}_{2} \mathrm{O} \\
0.77\end{array}$ & $\begin{array}{c}\mathrm{TiO}_{2} \\
0.23\end{array}$ \\
\hline Slag & $\mathrm{CaO}$ & $\mathrm{SiO}_{2}$ & $\mathrm{Al}_{2} \mathrm{O}_{3}$ & $\mathrm{MgO}$ & $\mathrm{SO}_{3}$ & $\mathrm{TiO}_{2}$ & $\mathrm{~K}_{2} \mathrm{O}$ & $\mathrm{MnO}$ & $\mathrm{Fe}_{2} \mathrm{O}_{3}$ \\
wt.\% & 39.12 & 32.69 & 13.45 & 8.12 & 3.53 & 1.41 & 0.72 & 0.53 & 0.43 \\
\hline
\end{tabular}

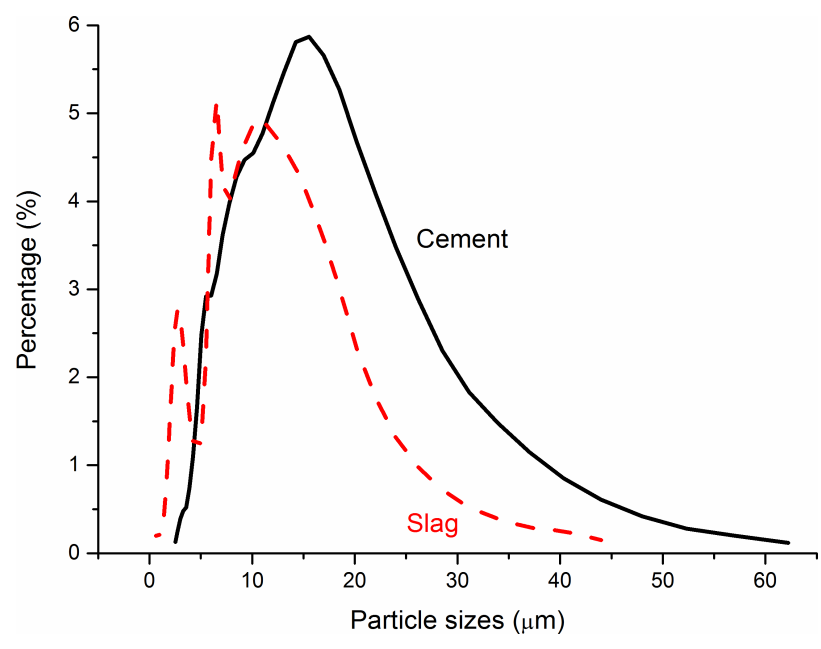

Fig. 1 Particle size distribution of cement and slag.

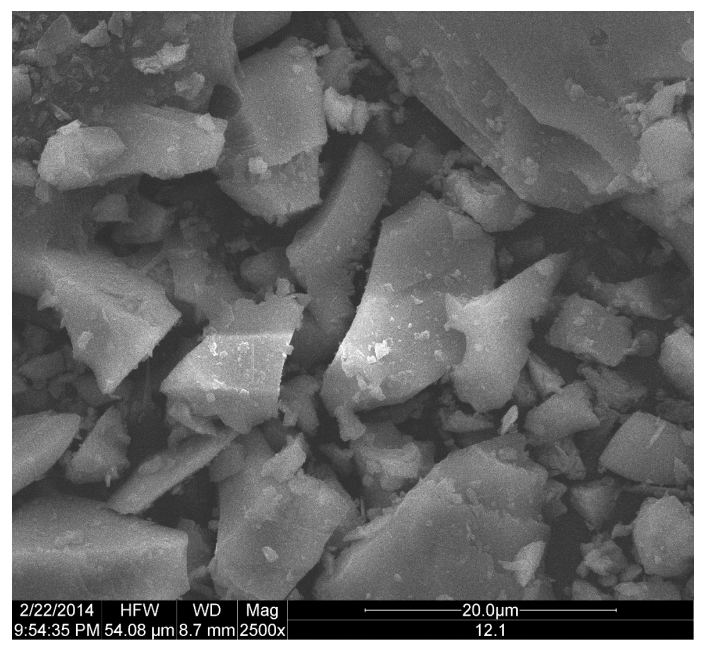

Fig. 2 Morphology of slag.<smiles>COCCOC(=O)C(C)(C)CC1(C)CCC1(CC(C)(C)CCOC)C(=O)O[Na]</smiles>

Fig. 3 Configuration of superplasticizer.

$0 \%, 0.05 \%, 0.1 \%, 0.15 \%, 0.2 \%$ and $0.25 \%$ by mass of cement, and thus the corresponding notations were set as SP0, SP0.05, SP0.1, SP0.15, SP0.2 and SP0.25.

\subsection{Analytical Methods}

\subsubsection{Electrical impedance and temperature measurement}

The NCIM was a newly promoted non-destructive method to study the hydration, pore size distribution, permeability, chloride ion migration and thermal conductivity of cement pastes 13 -15] Compared with traditional electrical impedance systems, metallic test electrodes were replaced by transformer and leakage current meter in NCIM. Other detailed information associated with this measurement can be found in Ref. 16. The impedance response of cement pastes with the volume of $1.35 \mathrm{~L}$ was measured and recorded for 3 days. Meanwhile, the surface temperature of cement pastes was tested by an infrared sensor during the same hydration period.

It was reported that cumulative pore volume of Portland and calcium sulfoaluminate cement pastes could be obtained from NCIM via the fractal analysis.117 The analysis procedure was demonstrated as: cumulative volume of pores $(V(\leq d))$ whose sizes were less than $d$ was determined by Eqs. (11) and (2):

$$
\begin{aligned}
V(\leq d)= & V_{s} \cdot \varphi \cdot\left[1-\left(\frac{d_{\min }}{d}\right)^{D_{\mathrm{f}}}\right], \\
\varphi= & {\left[(1-0.18) F^{-1 / 2}+0.18\right] } \\
& \cdot\left(400^{1 / 2}-F^{1 / 2}\right) /\left(400^{1 / 2}-1\right),
\end{aligned}
$$

where $V_{\mathrm{s}}$ was the apparent sample volume and equal to $1.35 \mathrm{~L}, \phi$ the porosity of cement pastes, $d_{\text {min }}$ the minimal pore diameter for NCIM and predicted as $6.2 \mathrm{~nm}$ according to the electrical double layers model, $D_{\mathrm{f}}$ the fractal dimension for pore size distribution and could be calculated from the combination of fractal electrical network and pore structure network, $10[15 \mid 16) F$ the formation factor and equal to $\rho / \rho_{0}, \rho$ the overall resistivity of the specimen under the applied frequency of $1 \mathrm{kHz}$ and $\rho_{0}$ the pore solution resistivity. The detailed determination of these parameters could be consulted in Refs. 15 and 16 . 


\subsubsection{Heat evolution}

The heat evolution of cement pastes incorporated with slag or superplasticizer was recorded continuously by isothermal calorimetry for 3 days. The fresh cement paste was injected into the glass ampoule of calorimetry via the syringe. The deionized water with the same weight as the paste was also injected into the other glass ampoule as a reference.

\subsubsection{Continuous correlation of cumulative heat release and pore volume}

The cumulative heat release $(Q)$ determined by heat evolution tests can be expressed as:

$$
Q=k V_{c},
$$

where $k$ is a parameter associated with the heat release rate at different hydration sections and $V_{\mathrm{c}}$ is the volume of raw cementitious materials that are involved in chemical reactions.

Besides, it is well documented that most of the expansive hydrated products will be precipitated at the surface of original cementitious materials during the reactions, accompanying by the heat release. The volume of hydrated products $\left(V_{\mathrm{hp}}\right)$ is figured out as:

$$
V_{\mathrm{hp}}=D V_{\mathrm{c}}
$$

where $D$ is the expansive parameter. It was reported by Xiao and Li 18 that 1 unit volume of cement produced approximately 2.06 unit volume of gel, while Sanahuja et al. ${ }^{19}$ considered that $D$ was 2.13 for fully hydrated products.

With regard to the cumulative pore volume, $V(\leq d)$, if the initial cumulative pore volume $\left(V_{0}\right)$ of material particle skeleton in the NCIM test and scaling factor $(f)$ are known, $V(\leq d)$ is solved as:

$$
V(\leq d)=V_{0}-f \cdot V_{\mathrm{hp}},
$$

where $f$ is defined to eliminate the volumetric difference between the heat evolution and NCIM tests. $V(\leq d)$ is derived directly from the NCIM test.

From the combination of Eqs. (31)-(5)), the explicit expression between $Q$ and $V(\leq d)$ is obtained as:

$$
\begin{aligned}
Q & =k V_{0} /(f D)-k V(\leq d) /(f D) \\
& =M+N V(\leq d),
\end{aligned}
$$

where $M$ and $N$ are fitting parameters. Obviously, $N$ enables to reflect the hydration kinetics (chemical reaction, crystal nucleation and precipitation) of cementitious material particles and scaling volumetric degree; $M$ further involves the volume information of initial particle skeleton of cementitious materials in the NCIM test.

\subsubsection{Compressive strength and setting time tests}

The influence of slag and superplasticizer on the early-age hydration of cement pastes is further studied by compressive strength and setting time tests. The fresh cement pastes incorporated with slag or superplasticizer were cast into $4 \mathrm{~cm} \times 4 \mathrm{~cm} \times 4 \mathrm{~cm}$ molds for compressive strength tests at 1 and 3 days. Six cubes for each mix proportion of cement paste were tested for the calculation of average value of compressive strength. The tests were undertaken with a loading rate $0.5 \mathrm{kN} / \mathrm{s}$.

At the same time, the setting time of cement pastes incorporated with slag or superplasticizer was measured by Vicat instrument according to ASTM C 191-99.

\section{RESULTS AND DISCUSSION}

\subsection{Non-Contact Impedance Measurement}

Figures 4414 show the modulus and phase of impedance of S0-S70 and SP0-SP0.25. It is evident from Figs. 4 to 8 that the addition of slag has a significant impact on the modulus and phase: the larger the amount of slag, the smaller the impedance modulus and phase lag. For instance, 3-day modulus and phase of impedance of S0 are approximately (3.21-4.23) $\mathrm{k} \Omega$ and up to $0.61 \mathrm{rad}$ in Fig. 4, while the ones of $\mathrm{S} 70$ are close to $(1.65-1.81) \mathrm{k} \Omega$ and $0.27 \mathrm{rad}$ in Fig. 8. With regard to the solid phase, the pozzolanic reaction of slag does not initiate until sufficient calcium hydroxide is formed in the pastes, $\frac{20]}{2}$ early hydration may be retarded with the replacement of cement by slag and the percolation of hydrated assemblage may be thus reached late, leading to small impedance modulus and phase. It was found that the similar hydration phenomena appeared in fly ash blended cement pastes, i.e. both the impedance modulus and phase of blended pastes decreased as fly ash amount increased, which indicated that the occurrence of percolation was retarded ${ }^{21}$ It was considered that the main hydrated products in hydrated slag blended cement pastes were C-A-S-H solid solution, calcium hydroxide, AFm, AFt, hydrotalcite 


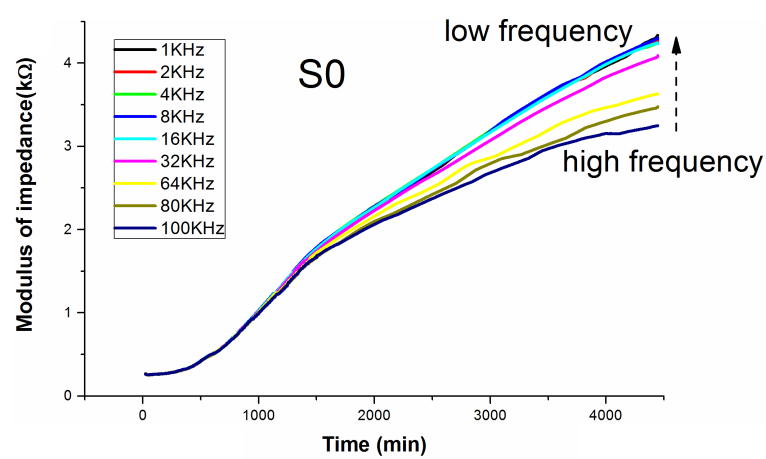

(a)

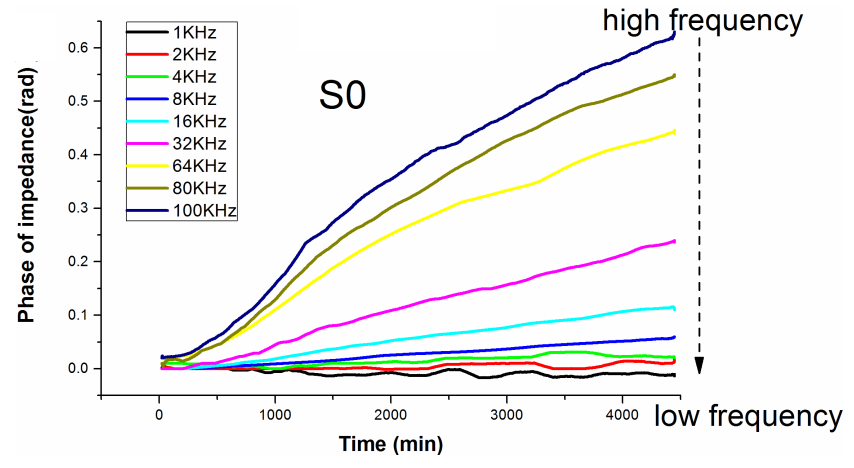

(b)

Fig. 4 Modulus and phase of impedance of S0.

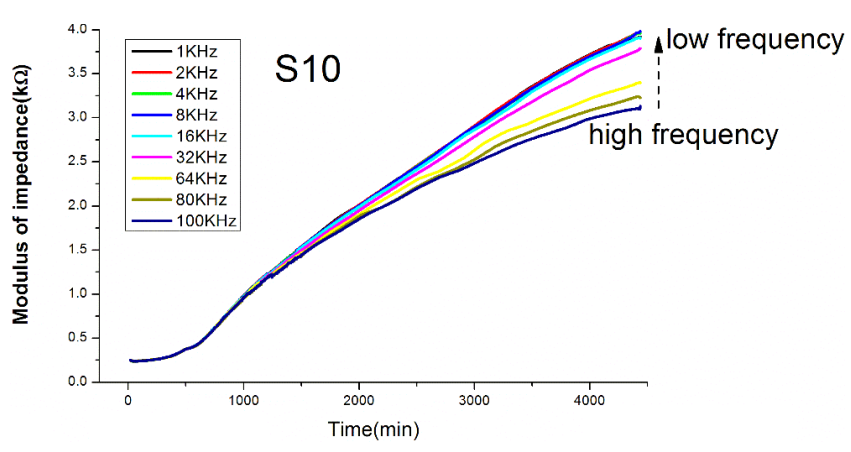

(a)

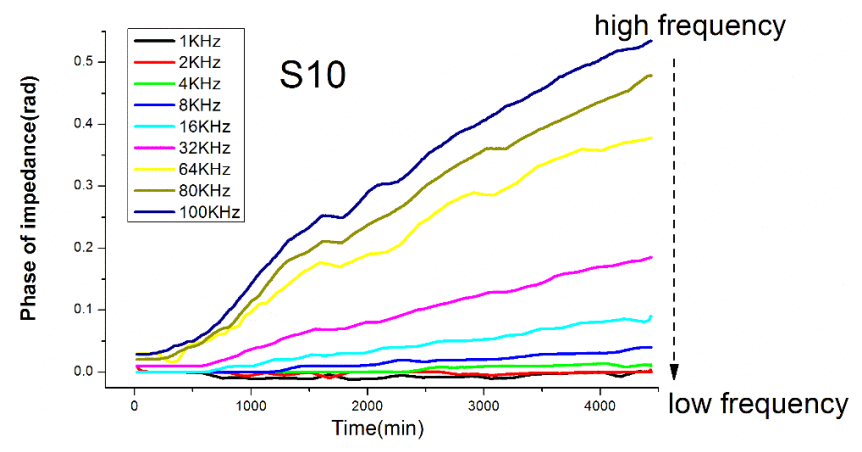

(b)

Fig. 5 Modulus and phase of impedance of S10.

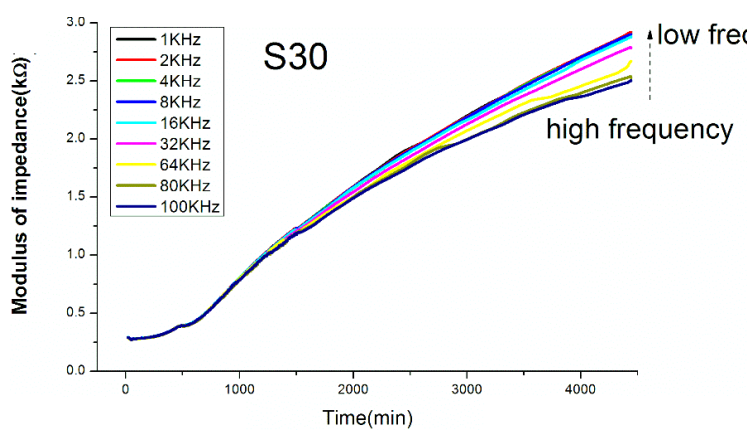

(a)

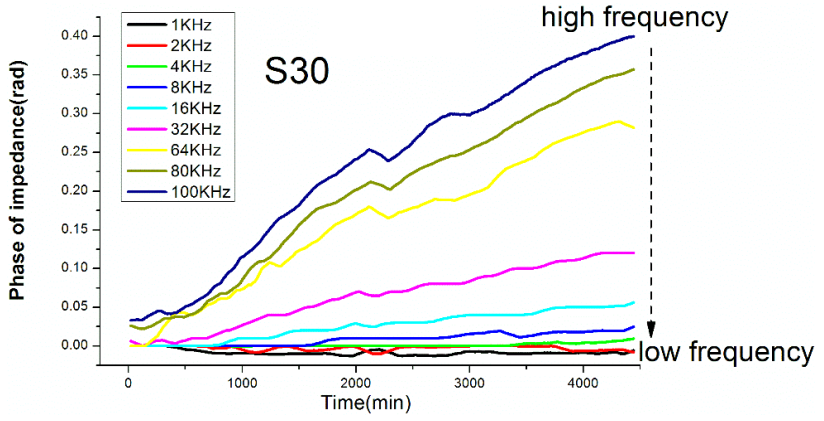

(b)

Fig. 6 Modulus and phase of impedance of S30.

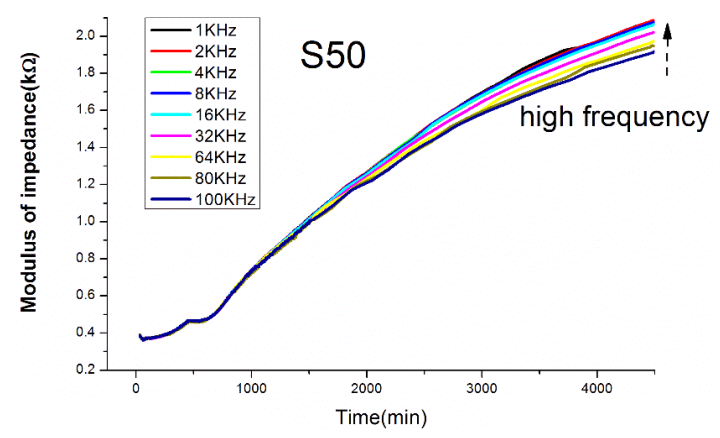

(a)

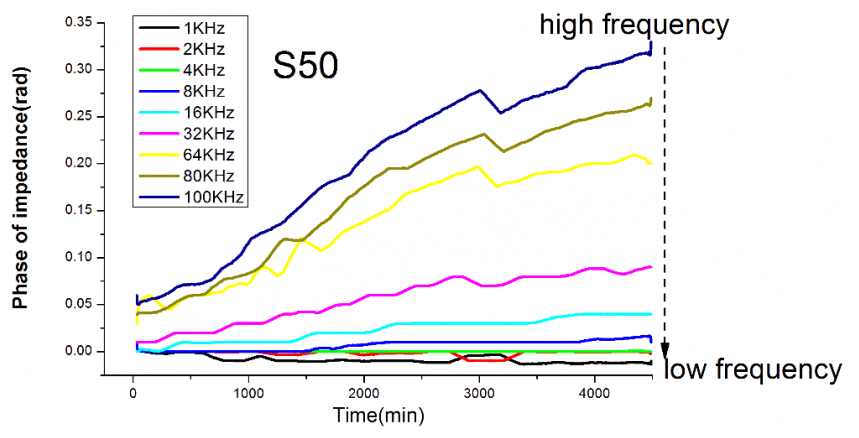

(b)

Fig. 7 Modulus and phase of impedance of S50. 
S. W. Tang et al.

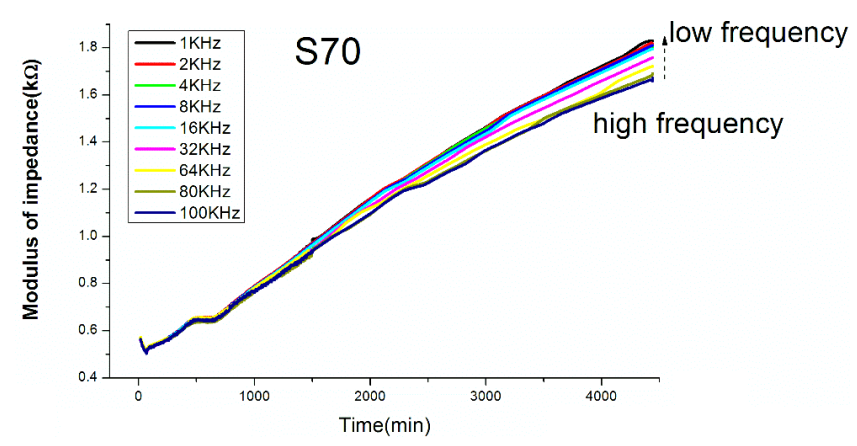

(a)

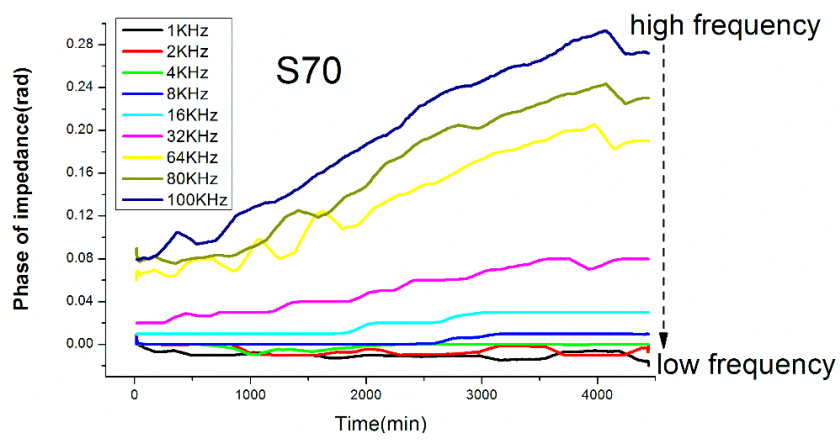

(b)

Fig. 8 Modulus and phase of impedance of S70.

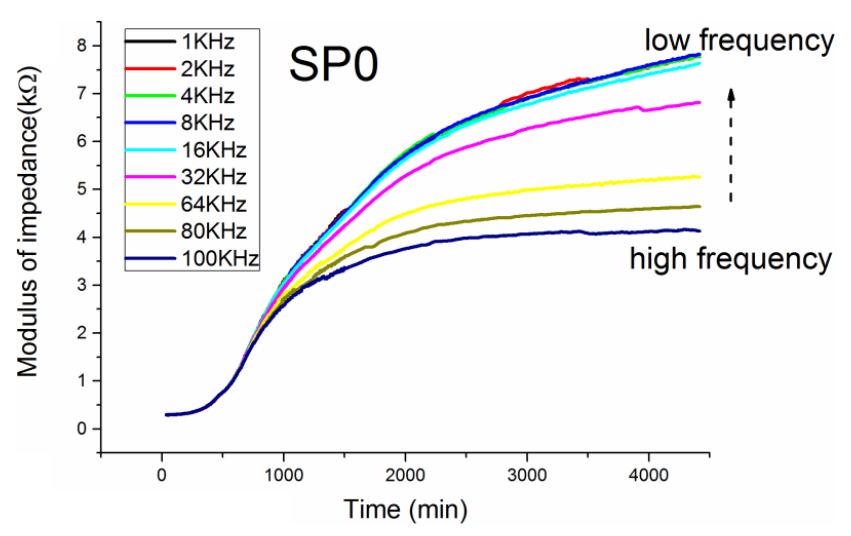

(a)



(b)

Fig. 9 Modulus and phase of impedance of SP0.



(a)

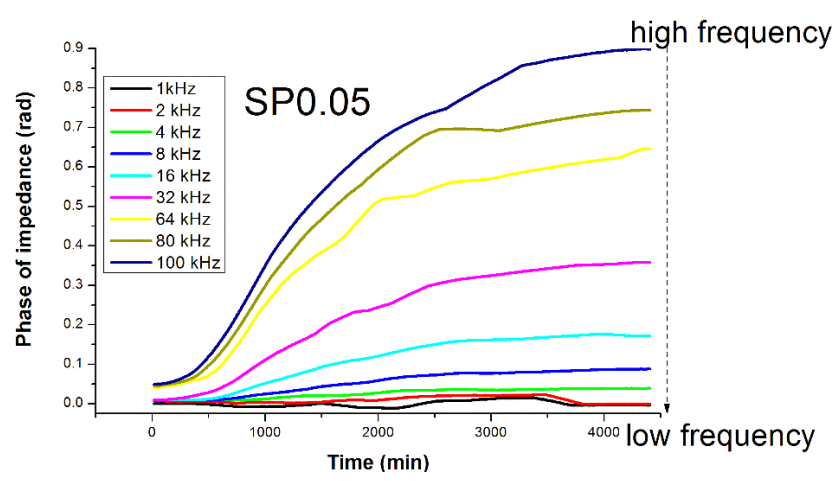

(b)

Fig. 10 Modulus and phase of impedance of SP0.05.

and monocarboaluminate. ${ }^{6}$ For the case of pore phase, some porous C-A-S-H products formed during the hydration process were able to uptake some alkali ions, perhaps resulting in low conductive performance of pastes. 21

From Figs. 9 to 14 the superplasticizer has relatively little retarded effect on the impedance response of cement pastes, compared with slag, which is examined by the sequences of 3-day modulus and phase of impedance at $1 \mathrm{kHz}$ : SP0.1 $(8.13 \mathrm{k} \Omega)>\operatorname{SP} 0(7.75 \mathrm{k} \Omega)>\operatorname{SP} 0.15(7.27 \mathrm{k} \Omega)>$ $\mathrm{SP} 0.2(7.03 \mathrm{k} \Omega)>\mathrm{SP} 0.05(6.98 \mathrm{k} \Omega)>\mathrm{SP} 0.25$ $(6.97 \mathrm{k} \Omega)$ and $\mathrm{SP} 0.2(4.19 \mathrm{rad})>\mathrm{SP} 0.15(4.18$ $\mathrm{rad})=\mathrm{SP} 0.1(4.18 \mathrm{rad})=\mathrm{SP} 0(4.18 \mathrm{rad})>\mathrm{SP} 0.25$ $(4.11 \mathrm{rad})>$ SP0.05 (4.09 rad). Recent studies considered that the retarded degree of superplasticizer 




(a)

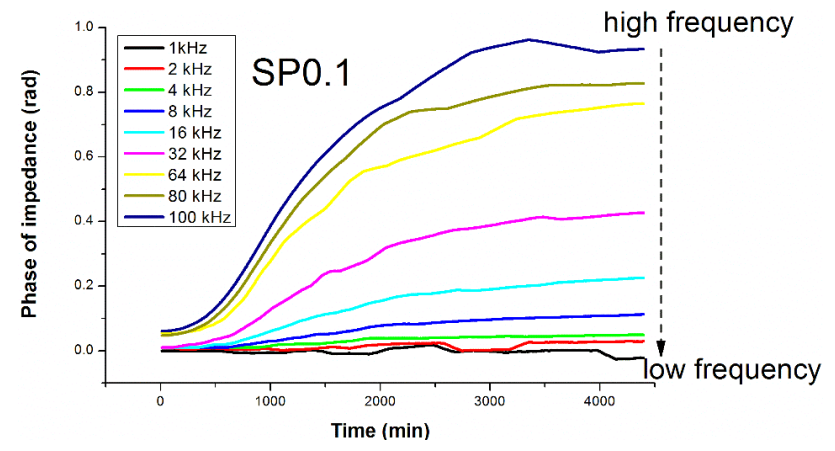

(b)

Fig. 11 Modulus and phase of impedance of SP0.1.



(a)



(b)

Fig. 12 Modulus and phase of impedance of SP0.15.



(a)



(b)

Fig. 13 Modulus and phase of impedance of SP0.2.



(a)

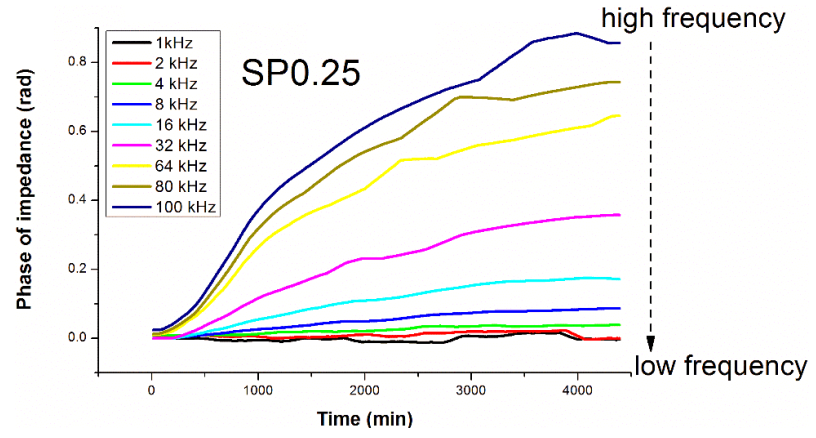

(b)

Fig. 14 Modulus and phase of impedance of SP0.25. 
was strongly dependent on not only the type of superplasticizer, but also the length of side chains, hydrolysis of ester and weight-average molecular weight.1122 Mollah et al. ${ }^{23}$ reviewed the interactions between cement and superplasticizer and claimed that the retarded effect of superplasticizer possibly originated from three aspects: (1) the adsorbed superplasticizer layers hindered the diffusion of water and ions at the cement-solution interface; (2) the $\mathrm{Ca}^{2+}$ ions in aqueous solution might be chelated by $-\mathrm{COO}^{-}$groups of superplasticizer molecules and thus the nucleation and precipitation of hydrates were inhibited and (3) the dispersion of cement grains caused by superplasticizers changed the growth kinetics and the morphology of hydrated phases 24

Figures 15 and 16] demonstrate the cumulative pore volume of slag blended cement pastes and pastes incorporated with superplasticizer. It should be emphasized that the cumulative pore volume in this work is actually referred to as the incremental pore volume whose pore sizes lie between $6.2 \mathrm{~nm}$ and $400 \mu \mathrm{m}$ in cement pastes since the theoretical minimal and maximal pore size cannot be obtained by experimental tests until now ${ }^{1}$ Special attention should be paid to three features of Fig. 15: (11) from the comparison of curves in Fig. 15, the role of slag in hydrating cement pastes is considerably distinct. Cumulative pore volume is quite sensitive to the slag amount. For example, at the very beginning of hydration, S0 and S10 have comparable large cumulative pore volume $(\approx 0.95 \mathrm{~L})$, whereas the cumulative pore volume of S70 is about $0.7 \mathrm{~L}$. This phenomenon may be interpreted by



Fig. 15 Cumulative pore volume of slag blended cement pastes.

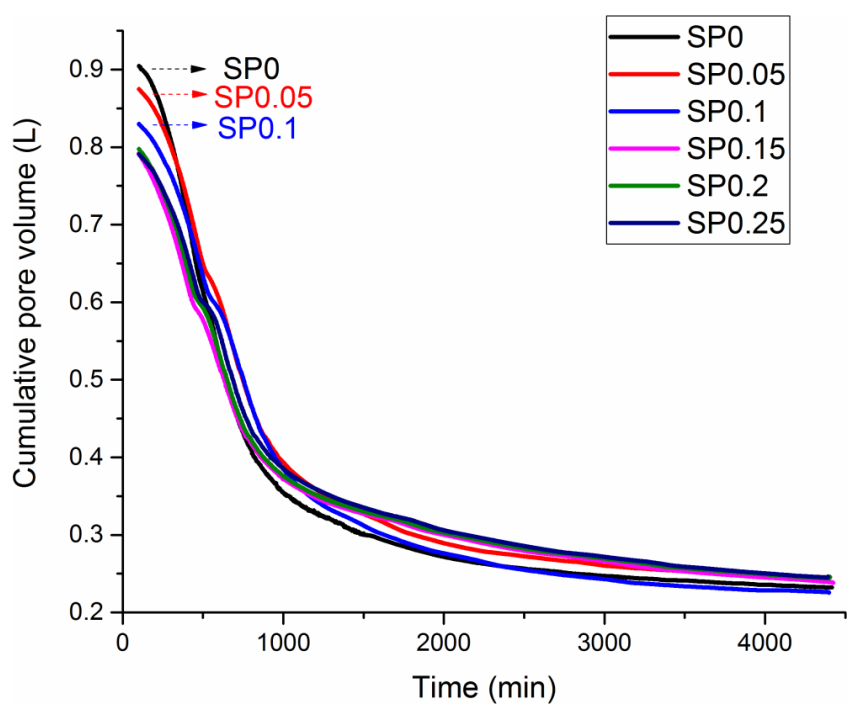

Fig. 16 Cumulative pore volume of cement pastes incorporated with SP.

the grading of cementitious materials in the fresh pastes: as demonstrated in Fig. 1, the fresh pastes with larger amount of slag with small particle size usually exhibit denser microstructure than ones with smaller amount and vice versa. (2) In the continuous hydration, an evident plateau appears between 450 and $640 \mathrm{~min}$ in Fig. 15, which indicates that an actual dynamic balance may be presented between the releasing and consuming of calcium hydroxide in this plateau.25] (3) Subsequently, the opposite data trend is observed in Fig. 15, and the sequence of cumulative pore volume is illustrated as: $\mathrm{S} 70>\mathrm{S} 50>\mathrm{S} 30>\mathrm{S} 10>\mathrm{S} 0$. This data trend is primarily caused by the retarded pozzolanic reaction. 14 When the pastes contain a good deal of slag, retarded pozzolanic reactions account for the low crystallization degree of pastes and the formation of poorly crystallized C-A-S-H phases (such as strätlingite and gismondine) is helpful to increase the cumulative pore volume of the pastes beyond all doubt. In fact, according to the previous study, the retarded pozzolanic reactions in high volume fly ash blended cement pastes were also helpful to the formation of poorly crystallized gismondine and gain of large cumulative pore volume. 21

With respect to the superplasticizer, it is noted that the cumulative pore volume is not much sensitive to the dosage of superplasticizer in Fig. 16. By comparison with Fig. 15] the variation of curves in Fig. 16 is not so distinct, which implies that superplasticizer used in this work has little effect on the evolution of pore framework in cement pastes. Experimental results by Ma et al. ${ }^{5}$ Khatib and 


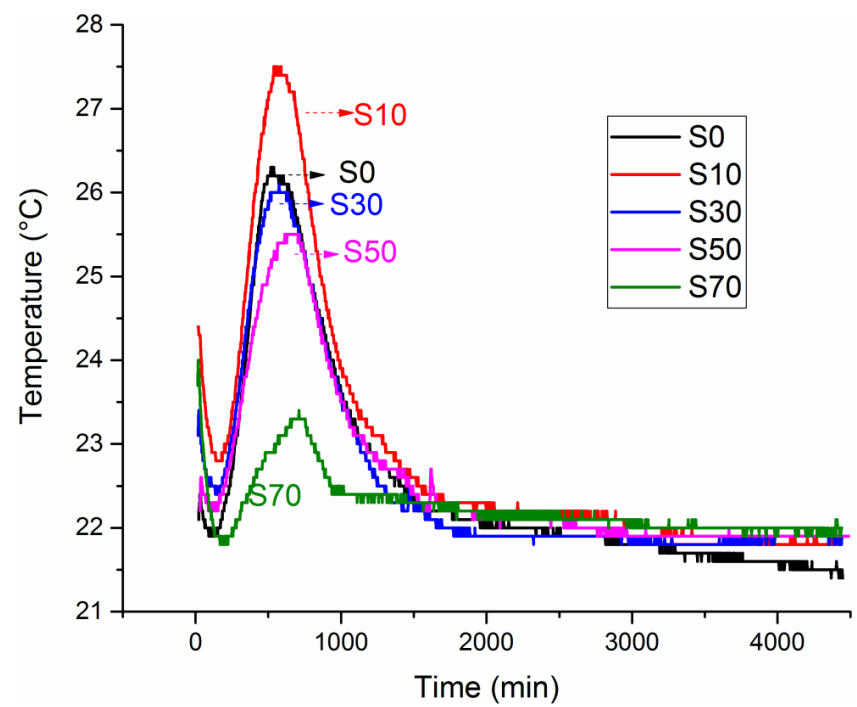

Fig. 17 Temperature development of slag blended cement pastes.

Mangat ${ }^{12}$ and Zhang and Kong 26 also revealed that variations of pore volume and porosity of cement pastes incorporated with different small dosages of superplasticizers were very small. Nevertheless, the water-reducing effect of superplasticizer is significantly highlighted at the very beginning of hydration due to the initial strong dispersion effect of superplasticizer in fresh pastes. Moreover, it can be observed that the cumulative pore volume in both Figs. [15] and 16] does not change much in the later stage. This is strongly associated with the gradual formation of pore structure in the pastes.

Temperature developments of slag blended cement pastes and pastes incorporated with superplasticizers are obtained from NCIM, as shown in Figs. 17 and 18 . In general, the temperature peak plateaus in Figs. 17 and 18 between 600 and $800 \mathrm{~min}$ are mainly attributed to accelerated chemical reactions and correspond to the large decrease rate of cumulative pore volume since the heat releasing accelerates the rapid reduction of pore structure in cement pastes, as noted in Figs. 15 and 16,, 8

With respect to slag case, the early-age dissolution of cement and/or glassy slag and reactions of $\mathrm{C}_{3} \mathrm{~A}$ are usually demonstrated by the heat releasing before $300 \mathrm{~min}$ and thus leading to a minor increase of temperature (about $2.5-4.5^{\circ} \mathrm{C}$ ) and the initial formation of small amount of certain kind of C-A-S-H. Subsequent chemical reactions in slag blended cement pastes give rise to a noteworthy increase of temperature. A quantity of concomitant poorly crystallized hydrated assemblage comes out and is strongly intermixed in the pastes. In addition,

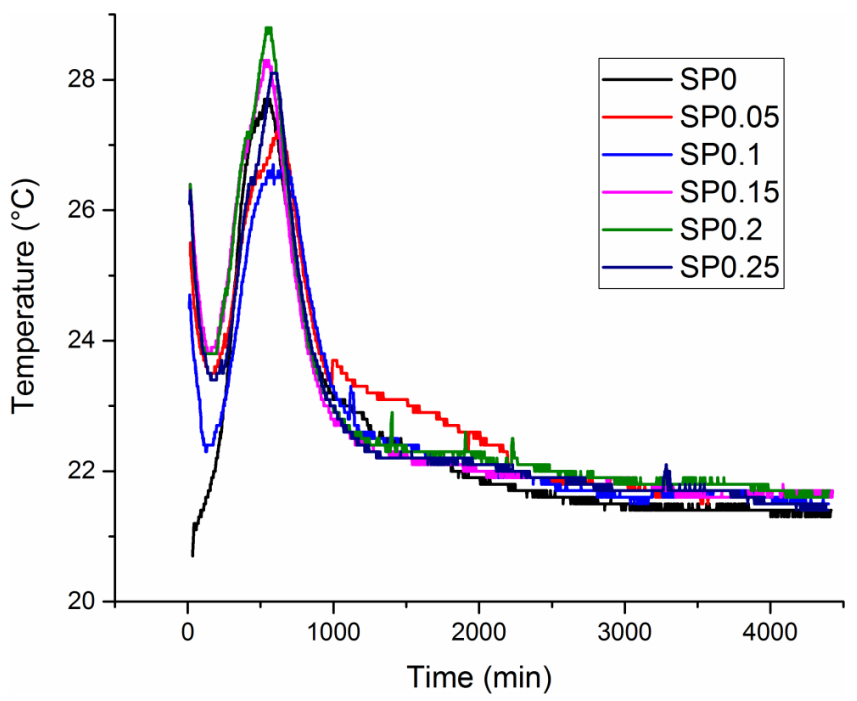

Fig. 18 Temperature development of cement pastes incorporated with SP.

it is expected that the values of strong temperature peaks are mainly related to the slag amount. Apart from S10 paste, negative relations are found between slag amount and values of strong temperature peaks as the excessive replacement of cement by slag restricts the formation and amount of calcium hydroxide in pastes, then reducing the chemical activation of blended cement pastes.

For the case of superplasticizer, compared with Fig. 17] the variations of peaks in temperature curves are slightly small in Fig. 18 For example, the peak temperature of $\mathrm{SP} 0.2$ is $28.8^{\circ} \mathrm{C}$, whereas the that of SP0.1 is around $26.7^{\circ} \mathrm{C}$. The overlapping of temperature curves is significantly prominent, which manifests that the incorporation of superplasticizer does not change the hydration of cement paste by the large. It seems that the $0.1 \%$ dosage of superplasticizer may yield the lowest temperature development in the paste.

\subsection{Heat Evolution of Cement Pastes}

Figure 19] demonstrates the heat rate development of slag blended cement pastes. From the comparison of temperature and heat rate development curves in Figs. 17 and 19, on the whole, the configuration of individual heat rate curve is very similar with the one of temperature curve. The incorporation of slag significantly reduces the peak values of heat rate curves. However, the positions and intensities of heat rate peaks are different from those of temperature curves in Fig. [17, The discrepancies 


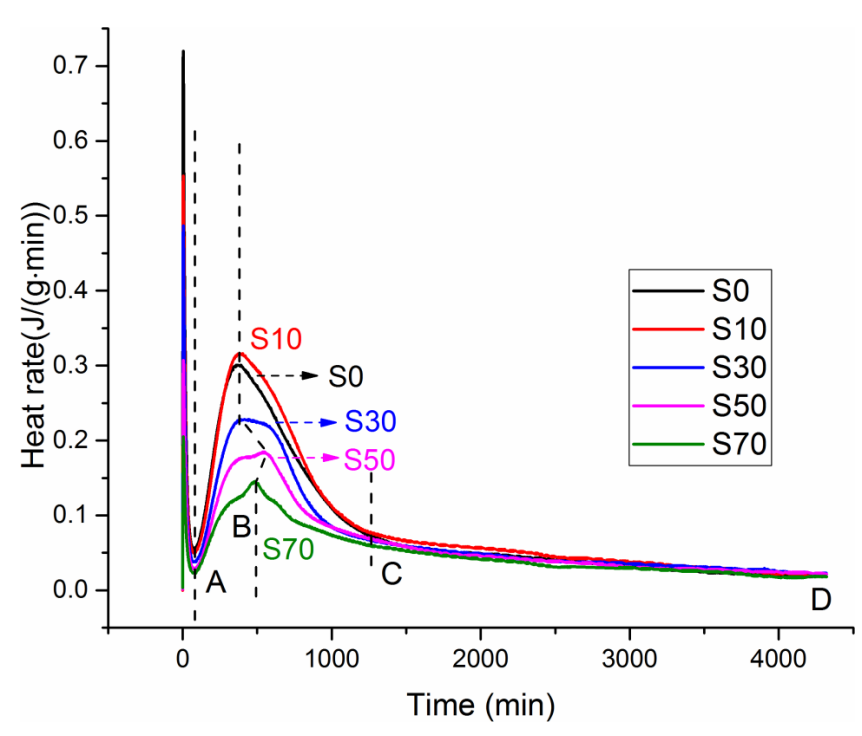

Fig. 19 Heat rate development of slag blended cement pastes.

of positions and intensities may lie in the different test conditions and sample volume: the temperature data recorded by NCIM are the surface temperature of $1.35 \mathrm{~L}$ cement pastes cured under the temperature $\left(20 \pm 2^{\circ} \mathrm{C}\right)$; whereas the heat evolution method only focusses on the liberated heat from small amount of cement pastes cured in a pseudoisothermal condition. 125

Figure 20 shows the cumulative heat release of slag blended cement pastes. There are several features in Fig. 20: (11) the cumulative heat release curves generally present "S" shape, which is consistent with impedance response in Figs. 48 . (2) The evolution curves of S0 and S10 have little differences. It has been confirmed again that

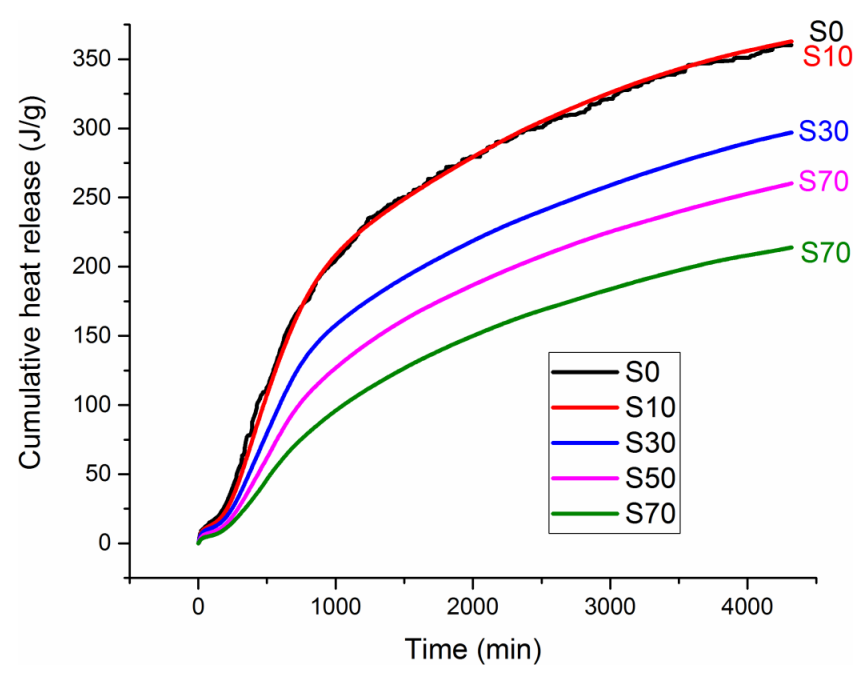

Fig. 20 Cumulative heat release of slag blended cement pastes.



Fig. 21 Heat rate development of cement pastes incorporated with SP.

the paste incorporated with small proper amount of slag is capable of keeping the similar performance of pure cement pastes. ${ }^{6}(3)$ Large amount of slag is beneficial to decrease the cumulative heat releasing by slowing down the hydration degree. (4) All the curves in Fig. 20 increase slowly in the later period as calcium hydroxide has not completely consumed by the slag hydration, even for a large replacement of slag and a long hydration time. Elakneswaran et al. $\underline{6}$ in 2016 considered that calcium hydroxide content was still kept around $5 \%$ in the pastes containing $67 \%$ slag replacement.

Figure 21 illustrates the heat rate development of cement pastes incorporated with superplasticizers. Obviously, the data trends in Figs. 19 and 21 are almost identical. Relatively speaking, two strong peaks in Fig. 21 do not retard too much even when $0.25 \%$ superplasticizer has been added into the pastes, which agrees very well with experimental results of impedance response. The heat rate curves are not closely linked with the dosages of superplasticizer. Besides, from Fig. 21, it is noted that the incorporation of superplasticizers leads to a prolonged induction period of cement pastes. $27 / 28$ It is reported that the prolonged phenomenon is predominantly due to the adsorption of superplasticizer molecules on the surface of hydrating cement grains and hydrated products and the complexation with $\mathrm{Ca}^{2+}$ ions $27 \mid 28$, on the one side, the adsorbed superplasticizer molecule layers are thought to slow down the diffusion of water and ions in the pastes; on the other side, the superplasticizers may form complexes with $\mathrm{Ca}^{2+}$ ions, which leads to both 
Continuous Microstructural Correlation of Slag/Superplasticizer Cement Pastes



Fig. 22 Cumulative heat release of cement pastes incorporated with $\mathrm{SP}$.

the reduction of $\mathrm{Ca}^{2+}$ concentration in solution and the inhibition of nucleation and growth of Cacontaining hydrated products.

Figure 22 shows the cumulative heat release of cement pastes incorporated with superplasticizers. The sharp increase of curves in Fig. 22 is believed to correspond to the acceleration period of hydration. In this period, the cement hydration steps into the rapid nucleation and growth of hydrates. Scrivener and Nonat $t^{29}$ and Cheung et al $\stackrel{30}{\cdot}$ reported that the maximum hydration rate in the acceleration period was associated with the amount of hydrate nucleus.

With respect to Figs. 21 and 22 it is observed that $0.1 \%$ superplasticizer provides favorable minimal heat rate and cumulative heat in the pastes. For cement pastes incorporated with superplasticizer, the hydration is continuously affected by further addition of superplasticizer, even though the second adsorption layer at the cement surface has already been saturated. The redundant superplasticizer mostly remains in the aqueous phase until the concentration of superplasticizer reaches the saturated level. 31

\subsection{Continuous correlation of cumulative heat release and pore volume}

This work attempts to continuously correlate the cumulative heat release to pore volume in different hydration sections in order to analyze the hydration kinetics of cement pastes incorporated with slag and superplasticizer. First of all, based on the configuration of heat evolution curves, illustrated in
Table 2 Two Characteristic Points, B and C, of Slag Blended Cement Pastes.

\begin{tabular}{ccc}
\hline Characteristic Points & B (min) & C (min) \\
\hline S0 & 374.01 & 1264.41 \\
S10 & 386.78 & 1262.45 \\
S30 & 388.81 & 1267.36 \\
S50 & 538.95 & 1267.43 \\
S70 & 484.71 & 1270.98 \\
\hline
\end{tabular}

Table 3 Two Characteristic Points, B and C, of Cement Pastes Incorporated with Superplasticizer.

\begin{tabular}{ccc}
\hline Characteristic Points & B (min) & C (min) \\
\hline SP0 & 364.9 & 1384.87 \\
SP0.05 & 436.11 & 1384.21 \\
SP0.1 & 702.36 & 1384.96 \\
SP0.15 & 489.85 & 1376.31 \\
SP0.2 & 523.65 & 1374.08 \\
SP0.25 & 452.11 & 1378.01 \\
\hline
\end{tabular}

Figs. 19]22 different hydration sections of cement pastes in 3 days can be roughly identified as $(\mathrm{A}-\mathrm{B})$, $(\mathrm{B}-\mathrm{C})$ and $(\mathrm{C}-\mathrm{D})$ sections according to four characteristic points marked in Figs. 19 and 21] Secondly, for the sake of simplicity, the hydration time, A and D, are considered as 100 and $4320 \mathrm{~min}$. Another two characteristic points, $\mathrm{B}$ and $\mathrm{C}$, determined by the heat rate figures are shown in Tables 2 and 3 , respectively.

When the data set of cumulative heat releasing and pore volume in different hydration sections in Figs. 15, 16, 20 and 22 is substituted into Eq. (6), the whole fitting procedure is achieved by Matlab program. Fitting parameters, $M$ and $N$, can be solved and shown in Tables 4 and 5 , respectively.

The fitting coefficients, $R^{2}$, are larger than 0.93 in Table 4, which indicates that there is a clear negative relation between cumulative heat releasing and

Table 4 Fitting Parameters of Slag Blended Cement Pastes.

\begin{tabular}{|c|c|c|c|c|c|c|c|c|c|}
\hline \multirow[t]{2}{*}{ Section } & \multicolumn{3}{|c|}{$A-B$} & \multicolumn{3}{|c|}{$\mathrm{B}-\mathrm{C}$} & \multicolumn{3}{|c|}{ C-D } \\
\hline & $M$ & $N$ & $R^{2}$ & $M$ & $N$ & $R^{2}$ & $M$ & $N$ & $R^{2}$ \\
\hline So & 731 & -765 & 0.96 & 410 & -378 & 0.97 & 563 & -698 & 0.93 \\
\hline $\mathrm{S} 10$ & 669 & -682 & 0.96 & 426 & -392 & 0.96 & 620 & -815 & 0.94 \\
\hline S30 & 555 & -603 & 0.96 & 373 & -361 & 0.95 & 544 & -706 & 0.94 \\
\hline $\mathrm{S} 50$ & 584 & -715 & 0.98 & 373 & -399 & 0.98 & 583 & -791 & 0.93 \\
\hline S70 & 476 & -677 & 0.98 & 607 & -854 & 0.97 & 531 & -743 & 0.95 \\
\hline
\end{tabular}


S. W. Tang et al.

Table 5 Fitting Parameters of Cement Pastes Incorporated with Superplasticizers.

\begin{tabular}{|c|c|c|c|c|c|c|c|c|c|}
\hline \multirow[t]{2}{*}{ Section } & \multicolumn{3}{|c|}{$\mathbf{A}-\mathbf{B}$} & \multicolumn{3}{|c|}{$\mathrm{B}-\mathrm{C}$} & \multicolumn{3}{|c|}{$\mathrm{C}-\mathrm{D}$} \\
\hline & $M$ & $N$ & $R^{2}$ & $M$ & $N$ & $R^{2}$ & $M$ & $N$ & $R^{2}$ \\
\hline SP0 & 351 & -369 & 0.97 & 349 & -391 & 0.87 & 573 & -106 & 0.79 \\
\hline SP0.05 & 290 & -321 & 0.95 & 345 & -399 & 0.92 & 561 & -105 & 0.88 \\
\hline SP0.1 & 199 & -235 & 0.94 & 372 & -566 & 0.91 & 481 & -891 & 0.88 \\
\hline SP0.15 & 214 & -264 & 0.95 & 397 & -581 & 0.88 & 449 & -673 & 0.85 \\
\hline SP0.2 & 225 & -275 & 0.95 & 390 & -567 & 0.87 & 467 & -744 & 0.89 \\
\hline SP0.25 & 268 & -328 & 0.96 & 375 & -504 & 0.89 & 502 & -833 & 0.92 \\
\hline
\end{tabular}

pore volume. Apparently, $M$ in A-B section is dominated by the initial heat releasing in Fig. 19, while small values of $M$ in $\mathrm{B}-\mathrm{C}$ section are in line with the decreasing section of heat rate in Fig. 19] Subsequently, values of $M$ exhibit diffusion-controlled phenomenon. $N$ also presents the similar evolution trend with $M$, but comparable low absolute values of $N$, apart from $\mathrm{S} 70$ paste, appear in $\mathrm{B}-\mathrm{C}$ section. Additionally, it is worth pointing out that fitting parameters, $M$ and $N$, show considerable variations with the slag amount. These variations in Table 4 may be attributed to different test conditions of NCIM and heat evolution method mentioned earlier.

The superplasticizer takes the governing effect on the separation of cementitious material particles in the fresh status. ${ }^{22}$ This separation phenomenon is demonstrated by the evolution of $M$ and $N$, namely, absolute values of $M$ and $N$ generally increase from $A-B$ to $C-D$ section. Furthermore, compared with Table 4 it is noted in Table 5 that the variations of $M$ and $N$ either in different sections or with different dosages of superplasticizer are not so large, which matches with temperature results presented in Fig. 18 as a whole.

\subsection{Compressive Strength and Setting Time}

Figure 23 shows the compressive strength of slag blended cement pastes. Comparatively speaking, the addition of slag has a negative effective on the gain of compressive strength. The pastes with large amount of slag usually exhibit low compressive strength and small impedance modulus due to the filling effect and retarded pozzolanic reactions. $\frac{32,33}{3}$

Figure 24 shows the setting time of slag blended cement pastes. Initial set time indicates the beginning of the setting process when the cement paste starts losing its plasticity, while the other important

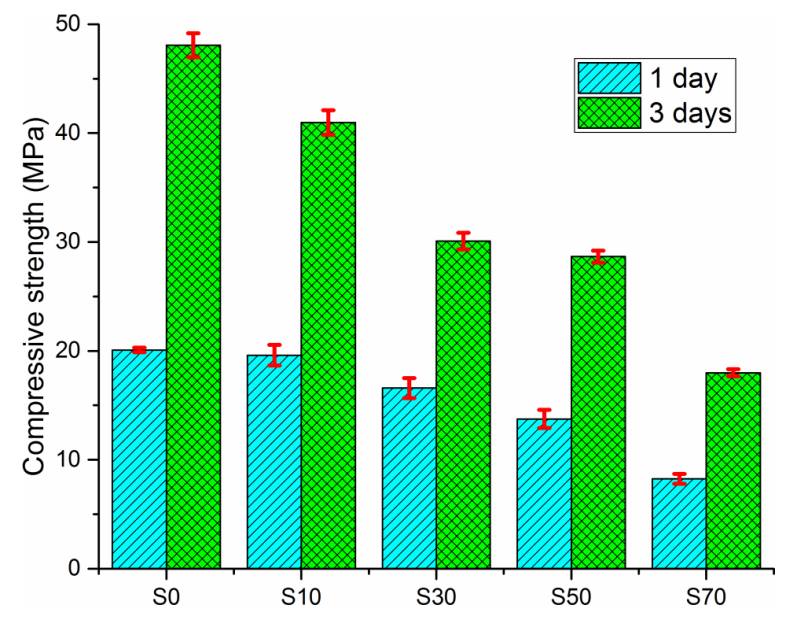

Fig. 23 Compressive strength of slag blended cement pastes.

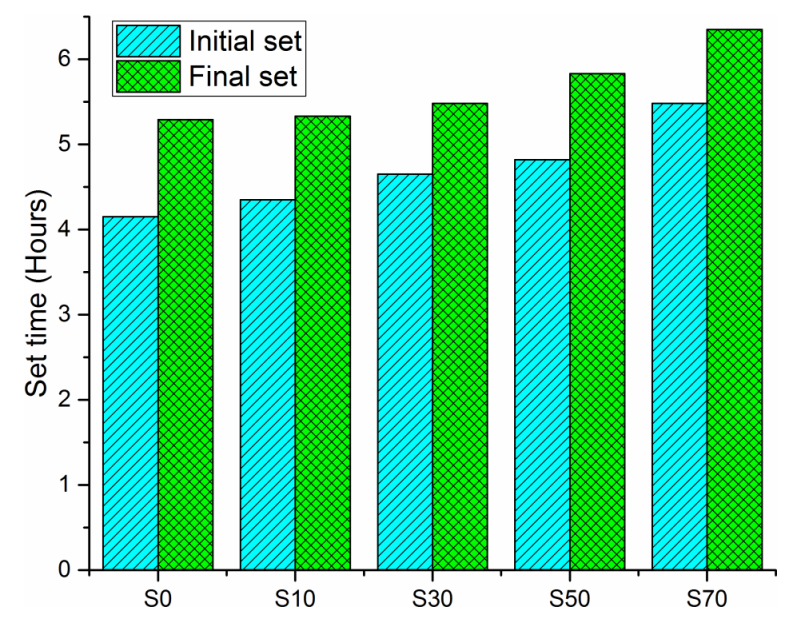

Fig. 24 Setting time of slag blended cement pastes.

setting time, namely, final set time is the time elapsed between the moment water is added to the cement and the time when the cement paste completely loses its plasticity and can resist certain definite pressure $\frac{8}{8}$ Initial and final set times are considered as empirical starting points of initial formation of pore structures of cementitious materials from time to time.

In like manner, the setting behaviors are influenced by the slag amount. Large amount of slag is expected to lead to long setting time of pastes. Furthermore, the compressive strength and setting time of slag blended cement pastes can be expressed by slag percentage $\left(S_{\%}\right)$ from fitting equations below:

$$
\begin{aligned}
C_{1 \mathrm{~d}} & =-0.166 \cdot S_{\%}+20.978, & & R^{2}=0.95, \\
C_{3 \mathrm{~d}} & =-0.396 \cdot S_{\%}+45.836, & & R^{2}=0.93, \\
T_{\mathrm{IS}} & =0.0174 \cdot S_{\%}+4.132, & & R^{2}=0.93, \\
T_{\mathrm{FS}} & =0.0149 \cdot S_{\%}+5.18, & & R^{2}=0.90,
\end{aligned}
$$




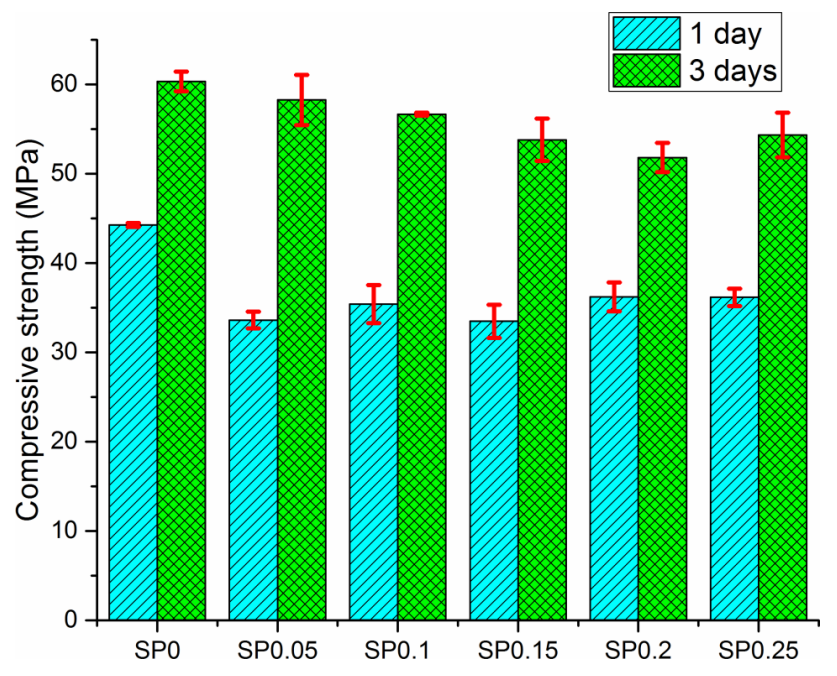

Fig. 25 Compressive strength of cement pastes incorporated with SP.

where $C_{1 \mathrm{~d}}$ and $C_{3 \mathrm{~d}}$ are the compressive strength of slag blended cement pastes at 1 and 3 days, and $T_{\mathrm{IS}}$ and $T_{\mathrm{FS}}$ are the initial and final setting times, respectively.

It can be concluded from Eqs. (7)-(10) that there are linear relations between compressive strength/setting time and the slag amount in the pastes.

Figure 25 shows the compressive strength of cement pastes incorporated with superplasticizers. It is particularly worth pointing out that unlike slag, the incorporation of superplasticizer in cement pastes has little effect on compressive strength, although some losses of compressive strength are observed in Fig. 25.

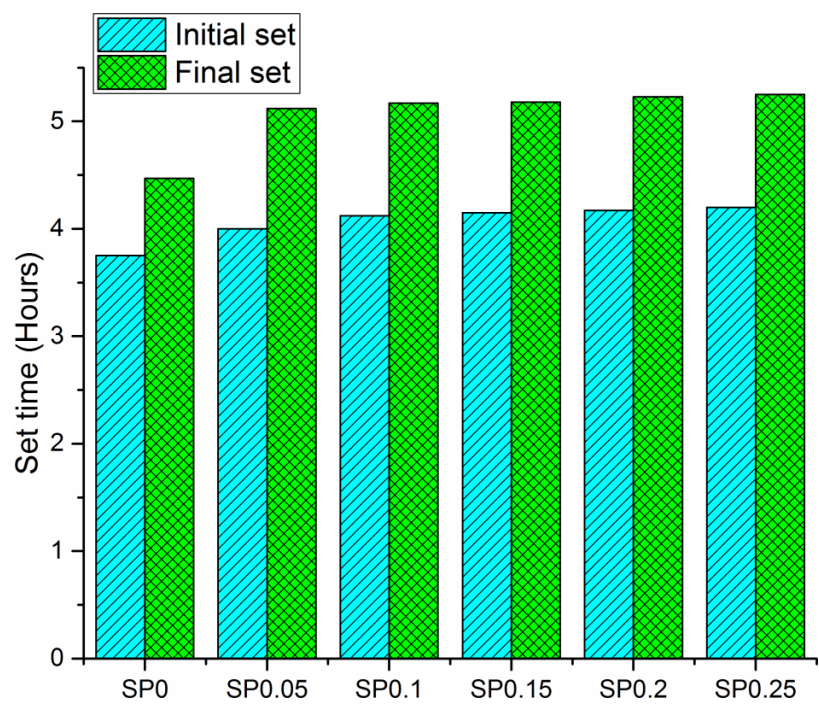

Fig. 26 Setting time of cement pastes incorporated with SP.
Figure 26 shows the setting time of cement pastes incorporated with superplasticizers. Both initial and final setting time of the pastes incorporated with superplasticizer is a little longer than those of the control paste, SP0. This indicates that the superplasticizer has a slight retarding effect on cement hydration at a given water-to-cement ratio. It seems that the addition of superplasticizer does not much affect the microstructure development of cement paste, $\stackrel{34}{a}$ as observed in Fig. [16.

\section{CONCLUSION}

This work preliminarily investigates the influence of slag and superplasticizer on the early-age hydration of cement pastes by NCIM, heat evolution method, compressive strength and setting time tests.

Modulus and phase of impedance, cumulative pore volume and temperature development obtained from NCIM reveal that large amount of slag leads to evident retarded pozzolanic reactions during the hydration. On the contrary, from experimental results by NCIM, the superplasticizer with selected dosage range from $0 \%$ to $0.25 \%$ in this work seems to have little effect on the hydration, although similar retarded phenomenon is observed. The retarded phenomenon is caused by the adsorption of superplasticizer molecules at the surface of hydrating cement grains and hydrated products and the complexation with $\mathrm{Ca}^{2+}$ ions.

Experimental results from heat evolution method, compressive strength and setting time tests verify these finding from NCIM. The continuous correlations of cumulative heat release and pore volume in different hydration sections via the fractal analysis are examined and present good linearity.

Indeed, the correlations of cumulative heat release and pore volume in this work do not take the temperature and humidity into consideration. This will be further polished in the future work.

\section{ACKNOWLEDGMENTS}

The supports from scientific research staring foundation for the China Ministry of Science and Technology under grant of 2015CB655101, National Natural Science Foundation of China (NSFC) under grant of 51602229, Hubei Province Science Foundation for Youths under grant of 2016CFB241, the introduction of talents under grant of 206410100031, Independent Scientific Research Project of Young Teachers under grant of 2042016kf0065 are gratefully acknowledged. 


\section{REFERENCES}

1. S. W. Tang, X. H. Cai, W. Zhou, H. Y. Shao, Z. He, Z. J. Li, W. M. Ji and E. Chen, In-situ and continuous monitoring of pore evolution of calcium sulfoaluminate cement at early age by electrical impedance measurement, Constr. Build. Mater. 117 (2016) 8-19.

2. C. Cetin, S. T. Erdoğan and M. Tokyay, Effect of particle size and slag content on the early hydration of interground blended cements, Cem. Concr. Compos. 67 (2016) 39-49.

3. F. Han, R. Liu, D. Wang and P. Yan, Characteristics of the hydration heat evolution of composite binder at different hydrating temperature, Thermochim. Acta 586 (2014) 52-57.

4. J. Stroh, M. C. Schlegel, W. Schmidt, Y. N. Thi, B. Meng and F. Emmerling, Time-resolved in situ investigation of Portland cement hydration influenced by chemical admixtures, Constr. Build. Mater. 106 (2016) 18-26.

5. B. Ma, M. Ma, X. Shen, X. Li and X. Wu, Compatibility between a polycarboxylate superplasticizer and the belite-rich sulfoaluminate cement: Setting time and the hydration properties, Constr. Build. Mater. 51 (2014) 47-54.

6. Y. Elakneswaran, E. Owaki, S. Miyahara, M. Ogino, T. Maruya and T. Nawa, Hydration study of slagblended cement based on thermodynamic considerations, Constr. Build. Mater. 124 (2016) 615-625.

7. Q. Zeng, D. Zhang, H. Sun and K. Li, Characterizing pore structure of cement blend pastes using water vapor sorption analysis, Mater. Charact. 95 (2014) 72-84.

8. Z. Li, Advanced Concrete Technology (John Wiley \& Sons, Hoboken, 2011).

9. G. Sun, L. Wang, L. Weng, J. Zhang, Z. Li and G. Chen, Determination of adsorption mechanism of polycarboxylate-ether based superplasticizers using crystallization, thermal and mass spectrometry methods, RSC Adv. 4(49) (2014) 25479-25485.

10. S. W. Tang, E. Chen, Z. J. Li and H. Y. Shao, Assessment of steady state diffusion of volatile organic compounds in unsaturated building materials based on fractal diffusion model, Build. Environ. 84 (2015) 221-227.

11. Y. Zhang and X. Kong, Correlations of the dispersing capability of NSF and PCE types of superplasticizer and their impacts on cement hydration with the adsorption in fresh cement pastes, Cem. Concr. Res. 69 (2015) 1-9.

12. J. M. Khatib and P. S. Mangat, Influence of superplasticizer and curing on porosity and pore structure of cement paste, Cem. Concr. Compos. 21(5-6) (1999) 431-437.

13. S. W. Tang, Z. J. Li, E. Chen and H. Y. Shao, Nonsteady state migration of chloride ions in cement pastes at early age, $R S C A d v$. 4(89) (2014) 4858248589.

14. S. W. Tang, Z. J. Li, H. Y. Shao and E. Chen, Characterization of early-age hydration process of cement pastes based on impedance measurement, Constr. Build. Mater. 68 (2014) 491-500.

15. S. W. Tang, Z. J. Li, H. G. Zhu, H. Y. Shao and E. Chen, Permeability interpretation for young cement paste based on impedance measurement, Constr. Build. Mater. 59 (2014) 120-128.

16. S. W. Tang, Z. J. Li, E. Chen and H. Y. Shao, Impedance measurement to characterize the pore structure in Portland cement paste, Constr. Build. Mater. 51 (2014) 106-112.

17. S. W. Tang, X. H. Cai, Z. He, W. Zhou, H. Y. Shao, Z. J. Li, T. Wu and E. Chen, The review of pore structure evaluation in cementitious materials by electrical methods, Constr. Build. Mater. 117 (2016) 273-284.

18. L. Z. Xiao and Z. J. Li, Early-age hydration of fresh concrete monitored by non-contact electrical resistivity measurement, Cem. Concr. Res. 38(3) (2008) $312-319$.

19. J. Sanahuja, L. Dormieux and G. Chanvillard, Modelling elasticity of a hydrating cement paste, Cem. Concr. Res. 37(10) (2007) 1427-1439.

20. Y. Gao, G. De Schutter, G. Ye, Z. Tan and K. Wu, The ITZ microstructure, thickness and porosity in blended cementitious composite: Effects of curing age, water to binder ratio and aggregate content, Compos. Part B-Eng. 60 (2014) 1-13.

21. S. W. Tang, X. H. Cai, Z. He, H. Y. Shao, Z. J. Li and E. Chen, Hydration process of fly ash blended cement pastes by impedance measurement, Constr. Build. Mater. 113 (2016) 939-950.

22. F. R. Kong, L. S. Pan, C. M. Wang, D. L. Zhang and N. Xu, Effects of polycarboxylate superplasticizers with different molecular structure on the hydration behavior of cement paste, Constr. Build. Mater. 105 (2016) 545-553.

23. M. Y. A. Mollah, W. J. Adams, R. Schennach and D. L. Cocke, A review of cement-superplasticizer interactions and their models, Adv. Cem. Res. 12(4) (2000) 153-161.

24. E. Janowska-Renkas, The effect of superplasticizers' chemical structure on their efficiency in cement pastes, Constr. Build. Mater. 38 (2013) 1204-1210.

25. S. W. Tang, H. G. Zhu, Z. J. Li, E. Chen and H. Y. Shao, Hydration stage identification and phase transformation of calcium sulfoaluminate cement at early age, Constr. Build. Mater. 75 (2015) 11-18.

26. Y. Zhang and X. Kong, Influences of superplasticizer, polymer latexes and asphalt emulsions on the pore structure and impermeability of hardened cementitious materials, Constr. Build. Mater. 53 (2014) 392-402. 
27. T. Sowoidnich, T. Rachowski, C. Rößler, A. Völkel and H.-M. Ludwig, Calcium complexation and cluster formation as principal modes of action of polymers used as superplasticizer in cement systems, Cem. Concr. Res. 73 (2015) 42-50.

28. H. von Daake and D. Stephan, Setting of cement with controlled superplasticizer addition monitored by ultrasonic measurements and calorimetry, Cem. Concr. Compos. 66 (2016) 24-37.

29. K. L. Scrivener and A. Nonat, Hydration of cementitious materials, present and future, Cem. Concr. Res. 41(7) (2011) 651-665.

30. J. Cheung, A. Jeknavorian, L. Roberts and D. Silva, Impact of admixtures on the hydration kinetics of Portland cement, Cem. Concr. Res. 41(12) (2011) 1289-1309.
31. J. Plank and B. Sachsenhauser, Impact of molecular structure on zeta potential and adsorbed conformation of $\alpha$-allyl- $\omega$-methoxypolyethylene glycol-maleic anhydride superplasticizers, J. Adv. Concr. Technol. 4(2) (2006) 233-239.

32. B. Kondraivendhan and B. Bhattacharjee, Strength and $\mathrm{w} / \mathrm{c}$ ratio relationship of cement based materials through pore features, Mater. Charact. 122 (2016) 124-129.

33. K. Wan and X. Xue, In situ compressive damage of cement paste characterized by lab source X-ray computer tomography, Mater. Charact. 82 (2013) $32-40$.

34. Y. Liao and X. Wei, Penetration resistance and electrical resistivity of cement paste with superplasticizer, Mater. Struct. 47(4) (2014) 563-570. 